\title{
Kinetics of Oxidative Depolymerization of k-carrageenan by Ozone
}

\author{
Aji Prasetyaningrum*, R. Ratnawati, Bakti Jos \\ Department of Chemical Engineering, Faculty of Engineering, Diponegoro University \\ Jl. Prof. Soedarto, SH, Kampus Undip Tembalang, Semarang 50275, Indonesia
}

Received: 21 ${ }^{\text {st }}$ November 2016; Revised: 27th January 2017; Accepted: $18^{\text {th }}$ February 2017

Depolymerization kinetics of $\mathrm{k}$-carrageenan by ozone treatment has been studied at various $\mathrm{pHs}$ and times. The purified $\mathrm{k}$-carrageenan with the initial molecular weight of $271 \mathrm{kDa}$ was dispersed in water to form $(1 \% \mathrm{w} / \mathrm{v})$ solution. Ozone with $80 \pm 2 \mathrm{ppm}$ concentration and constant flow rate of $3 \mathrm{~L}^{\mathrm{min}}{ }^{-1}$ was bubbled into the $\mathrm{k}$-carrageenan solution. The experiments were conducted at $\mathrm{pH}$ of 3,7 , and 10 at different times $(5,10,15$, and 20 minutes) of ozonation. The viscosity of the solution was measured using Ubbelohde capillary viscometer, which was then used to find the number-average molecular weight by Mark-Houwink equation. The number-average molecular weight data was treated using zero, first, and the second-order reaction kinetics model, to obtain the kinetics of $\mathrm{k}$-carrageenan depolymerization. The depolymerization is assumed to occur by random scission. The results show that the kinetics rate constant of $\mathrm{k}$-carrageenan depolymerization is higher at lower $\mathrm{pHs}$. The second-order model is more suitable for describing the kinetics of depolymerization of $\mathrm{k}$-carrageenan by ozonation process. The rate constants for the second-order kinetics model are $5.45 \times 10^{-4} \mathrm{~min}^{-1}, 1.27 \times 10^{-4} \mathrm{~min}^{-1}$, and $7.21 \times 10^{-5} \mathrm{~min}^{-1}$ for $\mathrm{pH} 3,7$, and 10 , respectively. The actual values of reaction order under acid and alkali conditions are ranging from 1.88 to 1.90. Copyright (c) 2017 BCREC Group. All rights reserved.

Keywords: Depolymerization; Kinetics; к-carrageenan; Ozone

How to Cite: Prasetyaningrum, A., Ratnawati, R., Jos, B. (2017). Kinetics of Oxidative Depolymerization of k-carrageenan by Ozone. Bulletin of Chemical Reaction Engineering \& Catalysis, 12 (2): 235-242 (doi:10.9767/bcrec.12.2.805.235-242)

Permalink/DOI: http://dx.doi.org/10.9767/bcrec.12.2.805.235-242

\section{Introduction}

$\mathrm{k}$-Carrageenan is a substantial gelling polysaccharide extracted from several species of red seaweed (Rhodophyceae). Structurally, it consists of repeating disaccharide units of alternating (1/3)- $a$-D-galactose- 4 sulfate and (1/4)- $\beta$-3, 6-anhydro-D-galactose residues [1-3]. The structure is depicted in Figure 1.

The size or degree of polymerization of $\mathrm{K}$ carrageenan plays a critical role in determining

* Corresponding Author.

E-mail: aji.prasetyaningrum@che.undip.ac.id

Telp.: +6224-7460058, Fax.: +6224-76480675 their application. The high-molecular-weight (HMW) k-carrageenan has limited applications as it is insoluble in water and it forms a viscous solution. By changing HMW $\kappa$-carrageenan into low molecular weight (LMW), $\kappa$-carrageenan increases the bioavailability and its potential

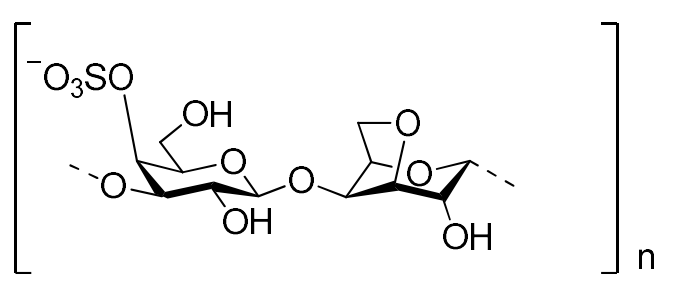

Figure 1. Basic structure of k-carrageenan [3] 
applications for biomedical applications [4-21].

LMW carrageenans have been produced by thermal depolymerization [20], acid hydrolysis $[6,16,21-25]$ and enzymatic hydrolysis [12,13, $15,26,27]$. There were several different techniques, such as microwave-assisted depolymerization [28], sonication [29-31], irradiation [17,32], and oxidation using $\mathrm{H}_{2} \mathrm{O}_{2}$ [21,33]. Acidic hydrolysis has been considered as a common and fast method to produce a series of carrageenan oligomers, but the use of chemicals causes a potential increase in the level of environmental pollution. The enzymatic method is not preferable because of relatively expensive and complex process [27].

Due to the high oxidation potential, ozone may be an alternative approach to achieving degradation of organic and inorganic compounds [34-53]. Ozone can react either indirectly (decomposition via a chain-reaction mechanism resulting in the production of hydroxyl free radicals) or directly (via selective reactions with substances in the water matrix). This combined effect makes ozone highly effective when compared to other chemicals. Therefore, the efficacy of an ozonation process is usually based on the effects of both reaction mechanisms, and these largely depend on the $\mathrm{pH}$, type and content of natural organic matter, and alkalinity [34]. Ozone reacts with organic compounds through various complex reactions forming reactive species. The primary nitrogen atom in amino acid, $\mathrm{C}-\mathrm{H}$ bond in alkanes, $\mathrm{S}-\mathrm{H}$ bond in sulfhydryl are vulnerable sites to be attacked by ozone $[34,39,45]$.

There have been many studies on ozone depolymerization of polysaccharides, such as guar gum [44], cellulose materials [45], starch $[38,40]$, gelatin [43], and chitosan [37,42,46]. The kinetics of depolymerization of a macromolecule by ozone treatment have also been reported. Chen et al. [47] studied the kinetics and pathways of oxidative degradation of $\mathrm{N}$ Nitrosopyrrolidine by ozone/UV process, while Dai et al. [48] investigated the kinetics of degradation of phenoxy acetic acid (PPA) in aqueous solution by ozonation at different initial $\mathrm{pH}$, the concentration of PPA and ozone dosage. Kinetic study of aflatoxins degradation in the presence of ozone with different ozone concentration and temperature have been reported by Agriopoulou et al. [49]. The degradation of aflatoxins was described by a first order kinetic equation. Lignin [50] and guar gum [44] were also degraded by ozone with first-order reaction pathway. On the other hand, several researchers utilized the pseudofirst-order model to describe the kinetics of depolymerization of N-Nitrosopyrrolidine [47], phenoxy acetic acid [48], textile dyes [51], wine distilleries wastewaters [52], and sulfamethoxazole [53].

The reports on the study of kinetics depolymerization of $\mathrm{k}$-carrageenan by ozone treatment were not available in the literature at the moment. Therefore, the aim of this work is to study the effect of $\mathrm{pH}$ on the depolymerization kinetics of $\mathrm{k}$-carrageenan solution using ozonation process.

\section{Materials and Methods}

\subsection{Materials}

The raw material used in this work was commercial k-carrageenan derived from seaweed Kappaphycus alvarezii, produced by CV. Karagen Indonesia, Semarang, Indonesia. For preparation, the k-carrageenan was dissolved in distilled water at $70{ }^{\circ} \mathrm{C}$ and stirred for 15 minutes. Purified $\mathrm{K}$-carrageenan was obtained by filtration and ethanol precipitation. The $\mathrm{pH}$ of the $\mathrm{k}$-carrageenan solution was adjusted by adding $\mathrm{HCl}$ with $37 \%$ of purity (E. Merck Cat. No. 100317) or $\mathrm{NaOH}$ with $>99 \%$ purity (E. Merck Cat. No. 104698). All chemical reagents were of analytical grade and directly used without further purification.

\subsection{Ozone treatment}

Purified k-carrageenan was completely dissolved in distilled water to form $1 \%(\mathrm{w} / \mathrm{v})$ solution. The experiments were carried out in a glass reactor equipped with an ozone bubble diffuser. Ozone gas with a concentration of $80 \pm 2 \mathrm{ppm}$ was produced by an ozone generator (Dipo Technology Indonesia). In this research, ozone was generated by passing air between two electrodes with a high potential difference (approximately $30 \mathrm{kV}$ ). Ozone was bubbled into the solution with a constant flow rate of 3 L.min ${ }^{-1}$. The experiments were conducted at $\mathrm{pH}$ of 3,7 , and 10 . The $\mathrm{pH}$ of the $\mathrm{k}$-carrageenan solution was adjusted with hydrochloric acid or sodium hydroxide solution and measured with a $\mathrm{pH}$ meter (Hanna Instruments HI 98107). The ozone treatment was conducted at temperature $29 \pm 1{ }^{\circ} \mathrm{C}$ and different times, i.e. 0 (control), 5, 10, 15 , and 20 minutes. Ozone-treated k-carrageenan was llected, rinsed with distilled water, and filtered with Buchner funnel. The residue was dried at $60{ }^{\circ} \mathrm{C}$ for $24 \mathrm{~h}$ in a forced air oven for further analysis. Schematic experimental of ozone treatment of $\mathrm{K}$-carrageenan is depicted in Figure 2. 


\subsection{Molecular weight determination}

For determination of molecular weight of ozone-treated $\mathrm{k}$-carrageenan, 5 different concentrations (0.016 to $1.0 \% \mathrm{w} / \mathrm{v})$ of ozonetreated $\mathrm{k}$-carrageenan solution were prepared. A portion of buffer solution of $\mathrm{pH} 7$ was added to adjust polysaccharide concentrations and to keep polysaccharide molecules from intermolecular aggregation. The efflux times of the solutions were measured using an Ubbelohde capillary viscometer (type 531 030c SchottGerate, Germany) in a constant temperature at $45.0 \pm 0.1{ }^{\circ} \mathrm{C}$. The intrinsic viscosity $([\eta])$ was calculated from the specific viscosity $\left(\eta_{s p}\right)$. The intrinsic viscosity is the average intercept of Huggins and Kraemer equation [54] in Equation (1).

$$
\frac{\eta_{s p}}{c}=[\eta]+k_{H}[\eta]^{2} c
$$

In this equation, $\eta_{s p}$, ([ $\left.\left.\eta\right]\right), k_{H}$, and $c$ are specific and intrinsic viscosity, Huggins constant, and the concentration of the solution, respectively. The specific viscosity $\left(\eta_{s p}\right)$ and the Huggins constant $\left(k_{H}\right)$ are dimensionless, while the intrinsic viscosity $([\eta])$ and the concentration $(c)$ have the units of mL.g-1 and g. $\mathrm{mL}^{-1}$, respectively. The value of $k_{H}$ for the $\mathrm{k}$-carrageenan solution is 0.35 [54].

The molecular weight of $\mathrm{k}$-carrageenan $(M)$ was calculated from the intrinsic viscosity data by Mark Houwink equation (Equation 2).

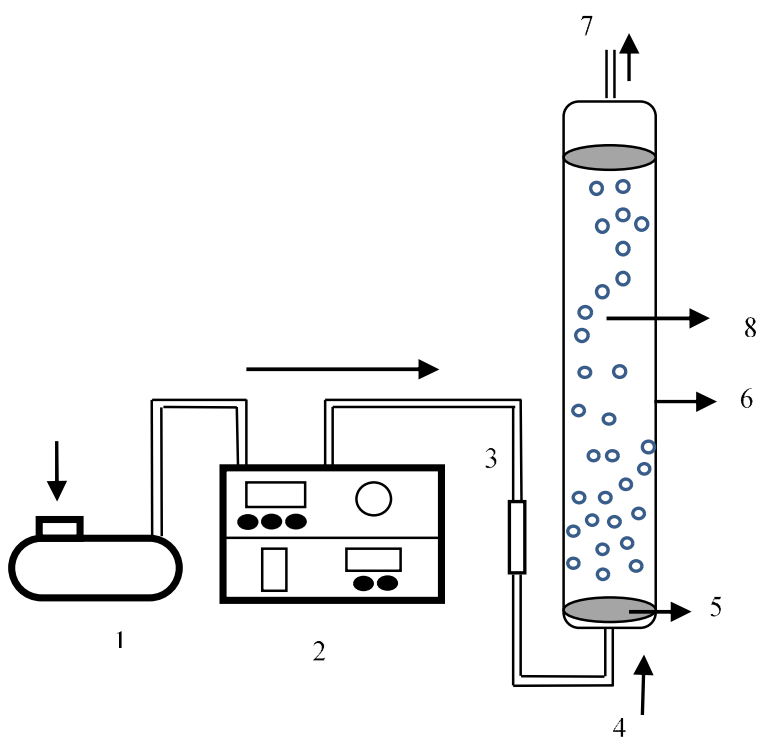

Figure 2. Schematic experimental of ozone treatment system : 1) compressor; 2) ozone generator; 3) flow meter; 4) ozone gas input; 5) sparger; 6) bubble column reactor; 7) ozone gas output; 8) k-carrageenan solution

$$
[\eta]=k_{M H} M^{\alpha}
$$

In this equation, $k_{M H}$ and $a$ are constants for a given system. In this work, the values of $k_{M H}$ and $a$ for k-carrageenan are 0.00598 and 0.90 , respectively. The symbols of $M$ and [ $\eta]$ are expressed in g.gmol $^{-1}$ and $\mathrm{mL} . \mathrm{g}^{-1}$, respectively [20].

\subsection{Mathematical treatment for kinetics model}

The dissociation of polymer molecules into smaller units is known as depolymerization. The simplest possible depolymerization occurs when a polymer formed by random polymerization undergoes depolymerization is by random bond breaking. In a random scission, all bonds of a polymer chain are equally susceptible to break with the rate proportional to the remaining unbroken bonds following Equations (3).

$$
-\frac{d\left(N_{0} p\right)}{d t}=k N_{0} p
$$

In this equation, $N_{o}$ denotes initial number monomers in the reaction mixture, $p$ is the fraction of monomers bonded in polymers, and $k$ is the reaction rate constant. The fraction of monomers bonded in polymers, $p$, can be related to the number-average molecular weight of polymer [55] as Equation (4).

$$
p=1-\frac{m}{M_{t}}
$$

The depolymerization behavior of carrageenan under ozone treatment is expressed according to the zero, first and second order reaction kinetics model [56]. Combination and integration from $t=0$ to $t=t$ of Eqs. (3) and (4) leads to Eqs. (5), (6), and (7) for zero order $\left(k_{z}\right)$, first order $\left(k_{f}\right)$, and second order $\left(k_{s}\right)$ reaction, respectively.

$$
\begin{aligned}
& \frac{1}{M_{t}}=\frac{k_{z}}{m} t+\frac{1}{M_{0}} \\
& \ln \left(1-\frac{m}{M_{t}}\right)-\ln \left(1-\frac{m}{M_{0}}\right)=-k_{f} t \\
& \frac{1}{\left(1-\left(\frac{m}{M_{t}}\right)\right)}=k_{s} t+\frac{1}{\left(1-\left(\frac{m}{M_{0}}\right)\right)}
\end{aligned}
$$

In these equations, $M_{t}$ and $M_{0}\left(\mathrm{D}_{\mathrm{a}}\right)$ are the number-average molecular weight of polymer at time $t$ and at time 0 , respectively, and $m$ $\left(D_{a}\right)$ is the average molecular weight of 
disaccharide unit (192 Da), based on the assumption that chain breakage occurs primarily at the 3,6-anhydrogalactose linkage $[20,22]$.

\section{Results and Discussion}

\subsection{Kinetics depolymerization of k-carrageenan by ozone treatment}

Three kinetics models (Equations (5), (6) and (7)) are employed in this work to describe the kinetics of ozone treatment for depolymerization of $\mathrm{k}$-carrageenan. Plot of $\left(1 / M_{t}\right)$ versus $t$, $\ln \left(1-m / M_{t}\right)-\ln \left(1-m / M_{0}\right)$ versus $t$, and $1 /\left(1-m / M_{t}\right)$ versus $t$ at various pHs are depicted in Figure 3.

The percent of average absolute deviation (\% AAD) of the model was also calculated. It is defined as Equation (8).

$$
\% A A D=\left[\frac{Y_{\text {exp }}-Y_{\text {calc }}}{Y_{\text {exp }}}\right] x 100 \%
$$

In this equation, $Y$ is the left-hand side of Equation (5)-(7). Subscript exp and calc refer to experimental and calculated values, respectively. The depolymerization rate constants $(k)$, correlation coefficient $\left(\mathrm{R}^{2}\right)$, and \%AAD for the models at various $\mathrm{pHs}$ are listed in Table 1.
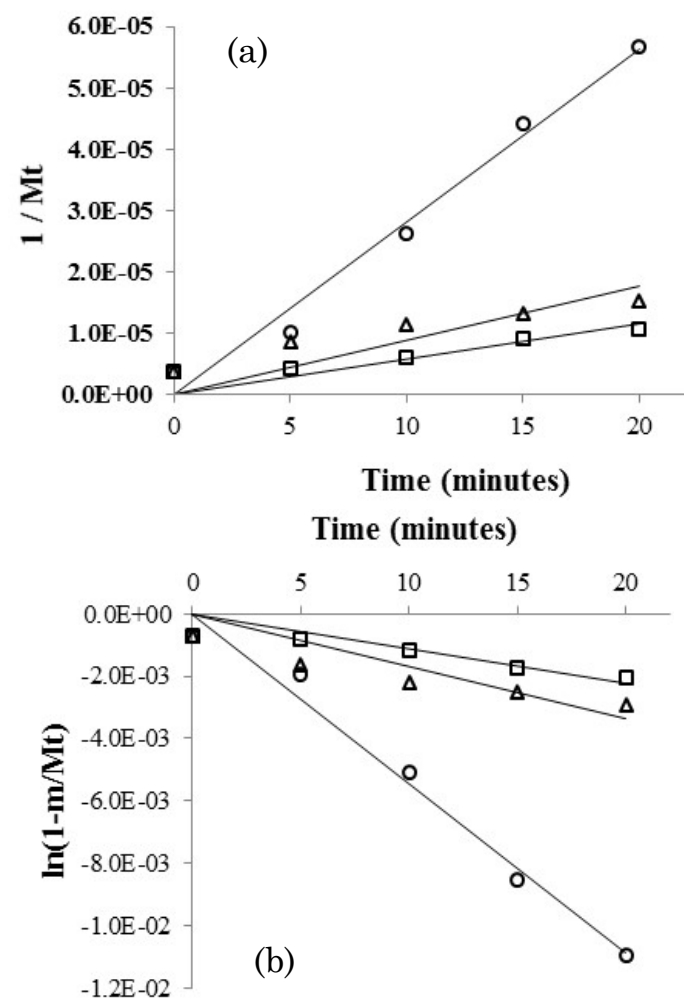

The correlation coefficient of the second order reaction is slightly larger than that of the zero and first-order reaction. It indicates that second order model is more suitable for describing the kinetics of depolymerization of $\mathrm{K}$-carrageenan by ozonation process. Arias et al. [57] reported kinetics data on the reactions of ozone with lignin and cellulose in aqueous solution at $\mathrm{pH} 2$ and 4 and temperature range of $20-40{ }^{\circ} \mathrm{C}$. The results gave the same trends, in which the ozonation of both lignin and cellulose at low temperature were also described by a second order kinetics scheme.

The kinetics equation of second order reaction is similar to pseudo-first order model [47,48,51-53]. In this work, the rate constant for second order model $\left(k_{s}\right)$ at $\mathrm{pH} 10$ is $7.21 \times 10^{-5} \mathrm{~min}^{-1}$. Ratnawati et al. [29] who degraded $\mathrm{k}$-carrageenan by ultrasound method found that the kinetics rate constant for pseudo-first order model at $30{ }^{\circ} \mathrm{C}$ and $\mathrm{pH} 10$ was $1.74 \times 10^{-6} \mathrm{~min}^{-1}$. The rate constant of ozone treatment is 41.4 fold of that of ultrasonic treatment. Lai et al. [20] reported that the kinetics rate constants of $\mathrm{k}$-carrageenan at 75-95 ${ }^{\circ} \mathrm{C}$ during 25 hours of thermal depolymerization were in the ranges of $2.0 \times 10^{-7}$ to $1.3 \times 10^{-6}$ $\mathrm{s}^{-1}$ or $1.2 \times 10^{-5}$ to $7.8 \times 10^{-5} \mathrm{~min}^{-1}$. The apparent value of kinetics rate constants of depolymerization by ozone treatment is 0.9-6.0 fold of thermal depolymerization.

\subsection{Effect of $\mathrm{pH}$ on kinetics of depoly- merization of $\mathrm{k}$-carrageenan by ozone treatment}

Table 1 shows that the rate constant value of second-order reaction $\left(k_{s}\right)$ for $\mathrm{pH} 7$ and $\mathrm{pH} 3$ are $1.27 \times 10^{-4} \mathrm{~min}^{-1}$ and $5.45 \times 10^{-4} \mathrm{~min}^{-1}$, respectively. The rate constant value of depolymerization of $\mathrm{k}$-carrageenan by ozone treatment at

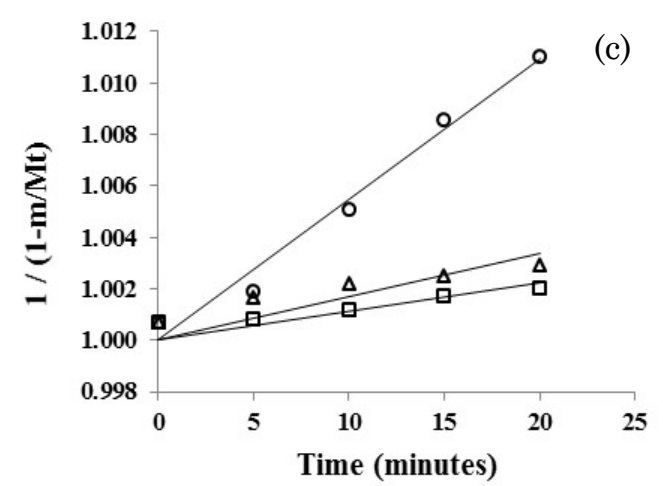

Figure 3. Time dependencies of (a) $1 / M_{t}$ according to zero-order model, (b) $\ln \left(1-m / M_{t}\right)$ according to firstorder model, and (c) $1 /\left(1-m / M_{t}\right)$ according to second-order model for $\mathrm{k}$-carrageenan at $\mathrm{pH} 3(\mathrm{o})$, $\mathrm{pH} 7$ $(\Delta)$, and $\mathrm{pH} 10(\square)$ 
lower $\mathrm{pH}$ is slightly larger than that at higher $\mathrm{pH}$. The apparent rate constant at $\mathrm{pH} 3$ is 4.3 fold of that at $\mathrm{pH}$ 7. Abad et al. [58] reported that the highest rate constants of reactions of $\mathrm{k}$-carrageenan were achieved at $\mathrm{pH} 2$. For cellulose oxidation by ozone in aqueous solution, it was found that the rate constant was 3 to 4 order of magnitude at lower $\mathrm{pH}$ [57].

At an acidic $\mathrm{pH}$, it is possible that hydrolysis reaction may have occurred resulting in the fragmentation of $\mathrm{K}$-carrageenan [58,22-24]. Singh and Jacobson [22] reported the kinetics constant of the first-order rate of hydrolysis of к-carrageenan at $\mathrm{pH} 2$ was $7.8 \times 10^{-7} \mathrm{~min}^{-1}$. For this research, the first-order rate kinetics constant of ozone treatment at $\mathrm{pH} 3$ is $5.42 \times 10^{-4}$ $\min ^{-1}$ and 694 fold of that of non-ozonation treatment at $\mathrm{pH} 2$. The results show that the combinations of ozone treatment and low $\mathrm{pH}$ gives the significant effect of increasing the rate constant value of $\mathrm{k}$-carrageenan depolymerization.

\subsection{Determination of reaction order of de- polymerization of k-carrageenan by ozone treatment}

The results of this work show that $\mathrm{k}$-carrageenan depolymerization by ozone treatment tends to follow the second order model. The mathematical modeling is needed to determine the actual value of the reaction order. The residual of the model and experimental was minimized using Solver of Microsoft Excel 2007 to determine the actual value of reaction order. The values of second order kinetics rate constants used in this calculation are $5.45 \times 10^{-4}$ $\min ^{-1}, \quad 1.27 \times 10^{-4} \mathrm{~min}^{-1}$, and $7.21 \times 10^{-5} \mathrm{~min}^{-1}$ for $\mathrm{pH} 3,7$, and 10, respectively. The apparent reaction order and the $\% \mathrm{AAD}$ at various $\mathrm{pHs}$ are listed in Table 2.

As presented in Table 2 that the values of reaction order of depolymerization of $\mathrm{k}$-carrageenan by ozone treatment at different $\mathrm{pHs}$ are 1.88-1.90, so it could be concluded that reaction is a non elementary reaction. The range of the overall \% $\mathrm{AAD}$ at $\mathrm{pH} 3,7$, and 10 are $10.21,10.00$, and $8.16 \%$, respectively. It indicates that second order reaction is more suitable for describing ozone depolymerization of $\mathrm{k}$-carrageenan.

\section{Conclusions}

The kinetics oxidative depolymerization of $\mathrm{k}$-carrageenan by ozone has been investigated. The highest rate constants of reactions of $\mathrm{k}$-carrageenan with ozonation treatment are achieved at lower $\mathrm{pH}$. For the similar conditions, the apparent value of rate constants of $\mathrm{k}$-carrageenan depolymerization by ozone treatment is higher than depolymerization by ultrasound methods and almost equal to thermal depolymerization. The actual values of reaction order $(n)$ are $1.88,1.89$, and 1.90 for $\mathrm{pH} 3,7$, and 10, respectively. For all $\mathrm{pHs}$, the ozonation of $\mathrm{k}$-carrageenan tends to follow the second order reaction model.

\section{Acknowledgement}

The authors acknowledge the financial support from DRPM Dikti Republic of Indonesia through a PUPT research project 2017.

Table 1. Kinetic rate constants at different initial $\mathrm{pH}$ for depolymerization of $\mathrm{k}$-carrageenan using

\begin{tabular}{cccccccccc}
\hline \multirow{2}{*}{$\mathrm{pH}$} & \multicolumn{3}{c}{ Zero-order reaction } & \multicolumn{3}{c}{ First-order reaction } & \multicolumn{2}{c}{ Second-order reaction } \\
\cline { 2 - 9 } & $k_{z}\left(\mathrm{~min}^{-1}\right)$ & $\mathrm{R}^{2}$ & \%AAD & $k_{f}\left(\mathrm{~min}^{-1}\right)$ & $\mathrm{R}^{2}$ & \%AAD & $k_{s}\left(\mathrm{~min}^{-1}\right)$ & $\mathrm{R}^{2}$ & \%AAD \\
\hline 3 & $4.94 \times 10^{-4}$ & 0.97 & 11.67 & $5.42 \times 10^{-4}$ & 0.98 & 11.62 & $5.45 \times 10^{-4}$ & 0.98 & 11.62 \\
7 & $1.22 \times 10^{-4}$ & 0.93 & 9.43 & $1.07 \times 10^{-4}$ & 0.96 & 9.08 & $1.27 \times 10^{-4}$ & 0.97 & 7.98 \\
10 & $6.32 \times 10^{-5}$ & 0.94 & 8.33 & $6.32 \times 10^{-5}$ & 0.94 & 8.17 & $7.21 \times 10^{-5}$ & 0.96 & 8.26 \\
\hline \multicolumn{2}{c}{ Over all } & 0.95 & 9.81 & & 0.96 & 9.62 & & 0.97 & 9.29 \\
\hline
\end{tabular}

Table 2. The apparent of reaction order depolymerization of k-carrageenan by ozone treatment

\begin{tabular}{cccc}
\hline $\mathrm{pH}$ & Initial $k_{s}\left(\mathrm{~min}^{-1}\right)$ & $n$ & $\% \mathrm{AAD}$ \\
\hline 3 & $5.45 \times 10^{-4}$ & 1.88 & 10.21 \\
7 & $1.27 \times 10^{-4}$ & 1.89 & 10.00 \\
10 & $7.21 \times 10^{-5}$ & 1.90 & 8.16 \\
\hline
\end{tabular}




\section{References}

[1] Necas, J., Bartosikova, L. (2013). Carrageenan: A Review. Veterinarni Medicina, 58(4): 187-205.

[2] Jiao, G., Yu, G., Zhang, J., Ewart, H.S. (2011). Chemical Structures and Bioactivities of Sulfated Polysaccharides from Marine Algae. Marine Drugs, 9(2): 196-223.

[3] Campo, V.L., Kawano, D.F., Silva, D.B., Carvalho, I. (2009). Carrageenans: Biological Properties, Chemical Modifications and Structural Analysis - A Review. Carbohydrate Polymers, 77: 167-180.

[4] Bixler, H.J., Porse, H. (2010). A Decade of Change in the Seaweed Hydrocolloids Industry. Journal of Applied Phycology. 23: 321335.

[5] Prajapati, V.D., Maheriya, P.M., Jani, G.K., Solanki, H.K. (2014). Carrageenan: A Natural Seaweed Polysaccharide and Its Applications - A Review. Carbohydrate Polymers, 105: 97112 .

[6] Wang, W., Zhang, P., Yua, G.L., Li, C.X., Hao, C., Qi, X., Zhang, L.J., Guan, H.S. (2012). Preparation and Anti-Influenza A Virus Activity of $\mathrm{k}$-Carrageenan Oligosaccharide and Its Sulphated Derivatives. Food Chemistry, 133(3): 880-888.

[7] Wijesekara, I., Pangestuti, R., Kim, S.K. (2011). Biological Activities and Potential Health Benefits of Sulfated Polysaccharides Derived from Marine Algae. Carbohydrate Polymers, 84(1): 14-21.

[8] Gomez-Ordonez, E., Jimenez-Escrig, A., Rupérez, P. (2014). Bioactivity of Sulfated Polysaccharides from the Edible Red Seaweed Mastocarpus stellatus. Bioactive Carbohydrates and Dietary Fibre, 3(1): 29-40.

[9] de Araújo, C.A., Noseda, M.D., Cipriani, T.R., Goncalves, A.G., Duarte, M.E.R., Ducatti, D.R.B. (2013). Selective Sulfation of Carrageenans and the Influence of Sulfate Regiochemistry on Anticoagulant Properties. Carbohydrate Polymers, 91(2): 483-491.

[10] Silva, F.R.F., Dore, C.M.P.G., Marques, C.T., Nascimento, M.S., Benevides, N.M.B., Rocha, H.A.O., Chavante, S.F., Leite, E.L. (2010). Anticoagulant Activity, Paw Edema and Pleurisy Induced Carrageenan: Action of Major Types of Commercial Carrageenan. Carbohydrate Polymers, 79: 26-33.

[11] Yamada, T., Ogamo, A., Saito, T., Uchiyama, H., Nakagawa, Y. (2000). Preparation of O Acylated Low-Molecular-Weight Carrageenans with Potent Anti-HIV Activity and Low Anticoagulant Effect. Carbohydrate Polymers, 41: 115-120.
[12] Yao, Z., Wu, H., Zhang, S., Du, Y. (2014). Enzymatic Preparation of $\mathrm{k}$-Carrageenan Oligosaccharides and their Anti-Angiogenic Activity. Carbohydrate Polymers, 101: 359-367.

[13] Haijin, M., Xiaolu, J., Huashi, G. (2003). A Carrageenan Derived Oligosaccharide Prepared by Enzymatic Degradation Containing Anti-Tumor Activity. Journal of Applied Phycology, 15(4): 297-303.

[14] Raman, R., Doble, M. (2015). k-Carrageenan from Marine Red Algae, Kappaphycus Alvarezii - A Functional Food to Prevent Colon Carcinogenesis. Journal of Functional Foods, 15: 354-364.

[15] Kalitnik, A.A., Barabanova, A.O.B., Nagorkaya, V.P., Reunov, A.V., Glazunov, V.P., Solov'eva, T.F., Yermak, I.M. (2013). Low Molecular Weight Derivatives of Different Carrageenan Types and their Antiviral Activity. Journal of Applied Phycology, 25(1): 65-72.

[16] Chiu, Y.H., Chan, Y.L., Tsai, L.W., Li, T.L., Wu, C.J. (2012). Prevention of Human Enterovirus 71 Infection by kappa Carrageenan. Antiviral Research, 95(2): 128-134.

[17] de Souza, L.A.R., Dore, C.M.P.G., Castro, A.J.G., de Azevedo, T.C.G., de Oliveira, M.T.B., Moura, M.F.V., Benevides, N.M B., Leite, E.L. (2012). Galactans from the Red Seaweed Amansia multifida and their Effects on Inflammation, Angiogenesis, Coagulation and Cell Viability. Biomedicine \& Preventive Nutrition, 2(3): 154-162.

[18] Qi, H., Zhang, Q., Zhao, T., Chen, R., Zhang, H., Niu, X., Li, Z. (2005). Antioxidant Activity of Different Sulfate Content Derivatives of Polysaccharide Extracted from Ulva Pertusa (Chlorophyta) In Vitro. International Journal of Biological Macromolecules, 37: 195-199.

[19] Pomin, V.H. (2010). Structural and Functional Insights into Sulfated Galactans: a Systematic Review. Glycoconj Journal, 27(1): 1-12.

[20] Lai, V.M.F., Lii, C.Y., Hung, W.L., Lu, T.J. (2000). Kinetic Compensation Effect in Depolymerization of Food Polysaccharides. Food Chemistry, 68(3): 319-325.

[21] Sun, Y., Yang, B., Wu, Y., Liu, Y., Gu, X., Zhang, H., Wang, C., Cao, H., Huang, L., Wang, Z. (2015). Structural Characterization and Antioxidant Activities of $\mathrm{K}$-Carrageenan Oligosaccharides Degraded by Different Methods. Food Chemistry, 178: 311-318.

[22] Singh, S. K., Jacobson, S.P. (1994). Kinetics of Acid Hydrolysis of $\mathrm{K}$-Carrageenan as Determined by Molecular Weight (SECMALLSRI), Gel Breaking Strength, and Viscosity Measurements. Carbohydrate Polymers, 23: 89-103. 
[23] Karlsson, A., Singh, S.K. (1999). Acid Hydrolysis of Sulfated Polysaccharides. Desulphation and the Effect on Molecular Mass, 38: $7-15$.

[24] Yuan, H., Song, J. (2005). Preparation, Structural Characterization and in Vitro Antitumor Activity of kappa-Carrageenan Oligosaccharide Fraction from kappaphycus striatum. Journal of Applied Phycology, 17(1): 713.

[25] Yu, G., Guan, H., Ioanoviciu, A.S., Sikkander, S.A., Thanawiroon, C., Tobacman, J.K., Linhardt, R.J. (2002). Structural Studies on kCarrageenan Derived Oligosaccharides. Carbohydrate Research, 337: 433-440.

[26] Wu, S.J. (2012). Degradation of KCarrageenan by Hydrolysis with Commercial a-Amylase. Carbohydrate Polymers, 89: 394396.

[27] Duan, F., Yu, Y., Liu, Z., Tian, L., Mou, H. (2016). An Effective Method for the Preparation of Carrageenan Oligosaccharides Directly from Eucheuma cottonii using Cellulase and Recombinant $\mathrm{k}$-Carrageenase. Algal Research, 15: 93-99.

[28] Zhou, G., Yao, W., Wang, C. (2006). Kinetics of Microwave Degradation of $\lambda$-Carrageenan from Chondrus Ocellatus. Carbohydrate Polymers, 64: 73-77.

[29] Ratnawati, R., Prasetyaningrum, A., Wardhani, D.H. (2016). Kinetics and Thermodynamics of Ultrasound-Assisted Depolymerization of $\mathrm{x}$-Carrageenan. Bulletin of Chemical Reaction Engineering \& Catalysis, 11: 48-58.

[30] Taghizadeh, M.T., Abdollahi, R. (2015). Influence of Different Degradation Techniques on the Molecular Weight Distribution of $\mathrm{K}$ Carrageenan. International Journal of Biochemistry and Biophysics, 3: 25-33.

[31] Yamada, T., Ogamo, A., Saito, T., Uchiyama, H., Nakagawa, Y. (2000). Preparation of OAcylated Low-Molecular-Weight Carrageenans with Potent Anti-HIV Activity and Low Anti-coagulant Effect. Carbohydrate Polymers, 41: 115-120.

[32] Abad, L.V., Kudo, H., Saiki, S., Nagasawa, N., Tamada, M., Fub, H., Muroya, Y., Lin, M., Katsumura, Y., Relleve, L.S., Aranilla, C.T., DeLaRosa, A.M. (2010). Radiolysis Studies of Aqueous k-Carrageenan. Nuclear Instruments and Methods in Physics Research Section B, 268(10): 1607-1612.

[33] Zúñiga, E., Matsuhiro, B., Mejías, E. (2006). Preparation of a Low-Molecular-Weight Fraction by Free Radical Depolymerization of The Sulfated Galactan from Schizymenia binderi (Gigartinales, Rhodophyta) and Its Anticoagulant Activity. Carbohydrate Polymers, 66: 208-215.
[34] Loures, C.C.A., Alcântara, M.A.K., Filho, H.J.I., Teixeira, A.C.S.C., Silva, F.T., Paiva, T.C.B., Samanamud, G.R.L. (2013). Advanced Oxidative Degradation Processes: Fundamentals and Applications. International Review of Chemical Engineering, 5: 102-120.

[35] Seydim, Z.B., Greene, A.K. (2004). Use of Ozone in the Food Industry. LWT-Food Science and Technology, 37: 453-460.

[36] Sandhu, H.P.S., Manthey, F., Simsek, S. (2012). Ozone Gas Affects Physical and Chemical Properties of Wheat Starch (Triticum Aestivum L). Carbohydrate Polymers, 87: 1261-1268.

[37] Seo, S., King, J.M., Prinyawiwatkul, W. (2007). Simultaneous Depolymerization and Decolorization of Chitosan by Ozone Treatment. Journal of Food Science, 72(9): C522526.

[38] Klein, B., Vanier, N.L., Moomand, K., Pinto, V.Z., Colussi, R., da Rosa Zavareze, E., Dias, A.R.G. (2014). Ozone Oxidation of Cassava Starch in Aqueous Solution at Different pH. Food Chemistry, 155: 167-173.

[39] Wang, Y., Hollingsworth, R.I., and Kasper, D.L. (1999). Ozonolytic Depolymerization of Polysaccharides in Aqueous Solution. Carbohydrate Research, 319: 141-147.

[40] Tiwari, B.K., Muthukumarappan, K., O'Donnell, C.P., Chenchaiah, M., Cullen, P.J. (2008). Effect of Ozonation on the Rheological and Colour Characteristics of Hydrocolloid Dispersions. Food Research International, 41(10): 1035-1043.

[41] Chan, H.T., Leh, C.P., Bhat, R., Senan C., Williams P.A., Karim, A. A. (2011). Molecular Structure, Rheological and Thermal Characteristics of Ozone-Oxidized Starch. Food Chemistry, 126: 1019-1024.

[42] No, H.K., Kim, S.D., Kim, D.S., Kim, S.K., Meyers, S.P. (1999). Effect of Physical and Chemical Treatment on Chitosan Viscosity, Journal of Chitin Chitosan, 4(4): 177-183.

[43] Cataldo, F. (2007). On the Action of Ozone on Gelatin. International Journal of Biological Macromolecules, 41: 210-216.

[44] Prajapat, A.L., Gogate, P.R. (2015). Intensification of Degradation of Guar Gum: Comparison of Approaches Based on Ozone, Ultraviolet and Ultrasonic Irradiations. Chemical Engineering and Processing, 98: 165-173.

[45] Simoes, R., Castro, J. (2001). Ozone Depolymerization of Polysaccharides in Different Materials. Journal of Pulp and Paper Science, 27 (3): 82-87

[46] Yue, W., Yao, P., Wei, Y., Mo, H. (2008). Synergetic Effect of Ozone and Ultrasonic Radia- 
tion on Degradation of Chitosan. Polymer Degradation and Stability, 93: 1814-1821.

[47] Chen, Z., Fang, J., Chihhao, F., Shang, C. (2016). Oxidative Degradation of NNitrosopyrrolidine by the Ozone/UV Process: Kinetics and Pathways. Chemosphere, 150: 731-739.

[48] Dai, Q., Chen, L., Chen, W., Chen, J. (2015). Degradation and Kinetics of Phenoxyacetic Acid in Aqueous Solution by Ozonation. Separation and Purification Technology, 142: 287292.

[49] Agriopoulou, S., Koliadima, A., Karaiskakis, G., Kapolos, J. (2016). Kinetic Study of Aflatoxins Degradation in the Presence of Ozone. Journal Food Control, 61: 221-226.

[50] Mbachu, R.A.D., Manley, J. (1981). Degradation of Lignin by Ozone II Molecular Weights and Molecular Weight Distributions of the Alkali-Soluble Degradation Products. Journal of Polymer Science: Polymer Chemistry Edition, 19: $2065-2078$.

[51] Zhang, R., Yuan, D.X., Liu, B.M. (2015). Kinetics and Products of Ozonation of C.I. Reactive Red 195 in a Semi-Batch Reactor. Chinese Chemical Letters, 26: 93-99.

[52] Lucasa, M.S., Peresa, J.A., Lan, B.Y., Puma, G.L. (2009). Ozonation Kinetics of Winery Wastewater in a Pilot-Scale Bubble Column Reactor. Water Research, 43: 1523-1532.
[53] Guo, W.Q., Yin, R.L., Zhou, X.J., Du, S.J., Cao, H.O., Yang, S.S., Ren, N.Q. (2015). Sulfamethoxazole Degradation by Ultrasound/Ozone Oxidation Process in Water: Kinetics, Mechanisms, and Pathways. Ultrasonics Sonochemistry, 22: 182-187.

[54] Vreeman, H.J., Snoeren, T.H.M., Payens, T.A.J. (1980). Physicochemical Investigation of $\mathrm{k}$-Carrageenan in the Random State. Biopolymers, 19: 1357-1354.

[55] Tanford, C. (1961). Physical Chemistry of Macromolecules. John Wiley \& Sons, Inc. New York.

[56] Beltran, F.J. (2005). Ozone Reaction Kinetics for Water and Wastewater Systems. Lewis Publishers, Taylor and Francis e-Library.

[57] Arias, A., Melo, R., Mariani, S., Zaror, C. (1997). Kinetics of Oxidation Reactions Between Ozone, Lignin and Cellulose. Celulosa Y Papel, 12-17.

[58] Abad L.V., Saiki, S., Kudo, H., Muroya, Y., Katsumura, Y., de la Rosa, A.M. (2007). Rate Constants of Reactions of $\mathrm{K}$-Carrageenan with Hydrated Electron and Hydroxyl Radical. Nuclear Instruments and Methods in Physics Research, 265: 410-413.

Selected and Revised Papers from The 2nd International Seminar on Chemistry (ISoC 2016) (Surabaya, 26-27 July 2016) (http://chem.its.ac.id/isoc-2016/) after Peer-reviewed by Scientific Committee of ISoC 2016 and Peer-Reviewers of BCREC journal 